\title{
Refugees Unwelcome? Changes in the Public Acceptance of Immigrants and Refugees in Germany in the Course of Europe's "Immigration Crisis"
}

\author{
Christian S. Czymara ${ }^{1}$, Alexander W. Schmidt-Catran² \\ ${ }^{1}$ Cologne Graduate School in Management, Economics and Social Sciences, University of \\ Cologne, Universitätsstr. 22a, Köln 50937, Germany \\ ${ }^{2}$ School of Social Sciences, University of Mannheim, A 5, 6, Mannheim 68131, Germany
}

This is a pre-copyedited, author-produced version of an article accepted for publication in European Sociological Review following peer review. The version of record (Volume 33, Issue 6, Pages 735-751) is available online at: https://doi.org/10.1093/esr/jcx071

\begin{abstract}
Based on an innovative design, combining a multi-factorial survey experiment with a longitudinal perspective, we examine changes in the public acceptance of immigrants in Germany from the beginning of the so-called "migration crisis" to after the sexual assaults of New Year's Eve 2015/16. In contrast to previous studies investigating similar research questions, our approach allows to differentiate changes along various immigrant characteristics. Derived from discussions making up the German immigration discourse during this time, we expect reduced acceptance especially of those immigrants who were explicitly connected to the salient events, like Muslims and the offenders of NYE. Most strikingly, we find that refugees were generally highly accepted and even more so in the second wave, whereas the acceptance of immigrants from Arab or African countries further decreased. Moreover, female respondents' initial preference for male immigrants disappeared. Contrary to our expectations, we find no changes in the acceptance of Muslims. We conclude that (1) public opinion research is well advised to match the particular political and social context under investigation to a fitting outcome variable to adequately capture the dynamics of anti-immigrant sentiment and that (2) the vividly discussed upper limits for refugees seem to be contrary to public demands according to our data.
\end{abstract}




\section{Introduction}

In 2015, Europe experienced a strong increase in immigration and asylum rates, which included a disproportionate high share of young male refugees, many originating from Syria, Afghanistan, and Iraq (Connor, 2016). For these immigrants and refugees, Germany was the most popular destination (ibd.). During this time, several violent acts took place which were directly or indirectly connected to Islam or immigration from Africa and the Middle East, including the Islamist attack on the staff of the satirical newspaper Charlie Hebdo, the related attack on a Jewish supermarket (January), the fatal attacks on a cultural centre and a Synagogue in Copenhagen in February, a series of attacks in the inner city of Paris with 130 fatalities, as well as the cancelation of a football match between Germany and the Netherlands in Hannover due to terror threat in November. This series of fatal events was followed by dozens of incidents of sexual assault and robbery at the festivities in several German cities on New Year's Eve (NYE) 2015/16, where the perpetrators were described to the police as men of "Arab or North African appearance" (DW, 2016). Many German media reports linked the sexual violence and robbery with the sexual harassment in crowds known from the protests at Cairo's Tahrir Square at the time of the Egyptian revolution (e.g., Lutz, 2016). After the event was uncovered, the story went viral and brought into question the heretofore rather liberal German refugee policy (Spiegel Online, 2016).

Such (potentially) threatening events are often linked to the erosion of public acceptance of immigrants by politicians and the media. While this effect is theoretically plausible, the reasoning is often based on anecdotal evidence. Direct scientific investigations of the effects of external events are rather rare. Furthermore, most of the studies which dealt with this question assumed a universal effect shaping attitudes toward all immigrants equally (e.g., Finseraas and Listhaug, 2013; Hopkins, 2010; Legewie, 2013). It is reasonable, however, to call this assumption into question (cf. de Rooij et al., 2015). This is because natives generally tend to evaluate different groups of immigrants in different ways (e.g., Bansak et al., 2016; Hainmueller and Hopkins, 2015; lyengar et al., 2013). Such differentiation may be even more important for the evaluation of immigrants after an external 
shock because such events are typically directly linked to stereotypes of specific ethnic groups, as in the case of the events on NYE 2015/16. We argue that prior research underestimated the effect of such events because it mixed up attitudes toward various immigrant subgroups even though most of them were not associated with the respective event. Accordingly, the effect of, for example, Islamist terror attacks on general attitudes to immigration found in previous research were modest compared with common expectations and, moreover, statistically significant in only some of the countries investigated (Finseraas et. al., 2011; Legewie, 2013) or even in none (Finseraas and Listhaug, 2013). An explanation of this surprising finding is that natives understand immigration not primarily as "Muslim immigration" and not because the events themselves are negligible. Our study allows differentiating the change in attitudes towards immigrants along various dimensions of immigrant characteristics.

We thus contribute to the literature by providing a more accurate effect of important events and thereby also a more nuanced understanding of the dynamics of public opinion toward immigrants in times of social tensions. This has important political implications because, tragically, such events are not unlikely to happen in Europe again in the future. Since public support of immigrants is a crucial prerequisite to successful integration, politicians should react adequately to such events. For example, bans or "upper limits" for refugees, as repeatedly demanded by many public speakers across Europe during our period of analysis, seem to contradict many natives' preferences according to our data.

We base our analysis on an innovative design which combines a multi-factorial survey experiment with a longitudinal perspective: respondents rated a set of hypothetical immigrant profiles in the beginning of the so-called "migrant crisis" and again shortly after NYE $2015 / 16$. We find not only that immigrants were generally rated more negatively in the second wave, but also that this negative effect was almost twice as large for migrants originating from the Middle East or Africa compared with those from a European neighbour of Germany. Both areas were at the centre of the German refugee debate in general and of the discussions regarding the assaults on NYE in particular. In contrast, we find that 
persecuted migrants ("refugees") were accepted even more in the second wave while changes in attitudes towards Muslim immigrants were not significant. Moreover, we show that female respondents' acceptance of male immigrants diminished over time.

\section{The Impact of External Events on Migration Related Attitudes: Theory and Evidence}

The determinants of migration-related attitudes have been intensively studied by social scientists who have examined the effects of individual attributes as well as contextual characteristics (Ceobanu and Escandell, 2010). Much of the recent literature indicates that socio-tropic and identity-related concerns are more important than self-interest (Hainmueller and Hopkins, 2014). The lion's share of these studies refer to Blumer's essay on group positions and collective threat perceptions, in which he argues that the dominant group of a society develops ethnic prejudices as a response to concerns about losing privileges to subordinate racial groups. Blumer particularly argues that "big events" play a crucial role in developing a concept of the racial out-group and are thus fundamental for the emergence of ethnic prejudice. He states: "It is the events seemingly loaded with great collective significance that are the focal points of the public discussion. The definition of these events is chiefly responsible for the development of a racial image and of the sense of group position" (Blumer, 1958: 6). From this sense of group position emerge fears that immigrants "alter the prevailing way of life or the foundation of national identity" (Ceobanu and Escandell, 2010: 318). However, previous research has paid only little attention to the effects of such events. There are only a few studies investigating "big events," often based on natural experiments. These studies exploit the fact that, in some cases, certain tragic events coincide with the field work period of large-scale survey programmes. For example, Legewie (2013) analyses the data from the European Social Survey (ESS) 2002 and Eurobarometer 2004 and draws upon the exogenous variation caused by the Islamist terror attacks in Bali on October 12, 2002 as well as the Madrid train bombings in March 2004. He finds significant effects in two out of nine countries for which the fieldwork period coincided with the terror attack in Bali. Analysis of the Madrid bombings reveal an especially 
strong effect for Spain itself, suggesting that events closer to home have a larger effect (Legewie, 2013). In a similar vein, Finseraas and Listhaug (2013), relying on the data of the fourth wave of the ESS, find that the Islamist terror attacks in Mumbai 2008 significantly increased fear of terrorism. According to their analysis, however, this fear does neither translate into support for illiberal interrogation techniques nor to more restrictive policy preferences. Moreover, Finseraas et al. (2011) analyse the second wave of the ESS and find that the brutal assassination of the Dutch film-maker Theo van Gogh by a radical Islamist in 2004 led to more restrictive policy preferences, although the effect is comparatively small and not significant for all countries, strikingly also not for the Netherlands. Similarly, Smiley, Emerson, and Markussen (2017) find that the immigration preferences of the residents of Copenhagen-area did not differ between those who were surveyed before and those surveyed after the shootings in Copenhagen 2015. However, Hopkins (2010) reports that US-Americans in counties which experienced a high inflow of migrants were in fact more negative about immigrants after the 9/11 attacks (Hopkins, 2010: $51-52)$.

In sum, the effects of significant events were surprisingly modest in most studies. An explanation for this is that large survey programs may not be able to sufficiently capture the central aspects of the public debates after such events. Most surveys programs typically ask rather general questions about immigration which are not tailored to specific events since they are hardly predictable.

Capturing these central aspects seems important, though, because, in Blumer's terms, public speakers define events and develop racial images by highlighting certain related aspects of ethnic out-group members, for example the aspects of origin or gender after NYE (see below). By calling attention to these aspects (and ignoring others), public speakers and the media shape which information is most easily accessible in natives' minds which, in turn, affects the criterions used for evaluating immigrants after these events (lyengar and Kinder 2010: $63 \mathrm{ff}$. ). 
For example, the ethnic riots in London in 2011 had an effect on prejudice toward Blacks and East European minorities, but not toward Muslims (de Rooij et al., 2015). The authors of this study conclude that "events that are linked more explicitly to minority groups" may "increase [...] prejudice by heightening perceived threats" (de Rooij et al., 2015: 381, emphasis added). This implies that the effect of destabilizing events is likely to decrease natives' acceptance of certain minority groups more than others. We take up this reasoning and put it to the test by making use of intra-individual variation not only between two time points but also regarding the acceptance of different immigrant subgroups.

\section{Germany's Immigration and Refugee Discourse before and after New Year's Eve} 2015/16

In 2015, more than 1.3 million asylum seekers first-registered in EU member states, a number more than twice as large as in the year before. More than a third of these refugees applied for asylum in Germany, making it the most popular destination in Europe (Connor, 2016). Thus, Germany by then was one of the key political players in the so-called European "migrant crisis." Accordingly, immigration and the admission of refugees had been prominently discussed in Germany during our time of analysis. Figure 1 graphs this quantitatively, depicting the number of daily articles about immigration in three prestigious German online media (Spiegel Online, Welt Online, and Zeit Online), with several million unique visitors per month each. ${ }^{1}$ It appears that media debates about immigration were relatively low in general during the first survey wave in April 2015. ${ }^{2}$ As the number of immigrants and refugees steadily increased in late summer 2015, shown by the circles, immigration stories about Africa and the Middle East and about Islam came more into focus.

This strong increase in asylum applications was accompanied by fundamental, and partly violent, protests against the German immigration and asylum policy. The most prominent example is the so-called Patriotic Europeans Against the Islamisation of the West (Occident) (PEGIDA) movement. Starting as a weekly protest march in Dresden already in autumn 2014, different branches of PEGIDA formed in various cities in Germany, attracting 
from a few dozens to several thousands of participants every week. A significant proportion of the German civil society, however, was also characterized by a high degree of openness and willingness to help the newcomers (Knobbe et al., 2015). The German public was therefore characterized by a marked divide over the country's immigration policy in general and the question of how to deal with different kinds of (potential) immigrants in particular.

Figure 1: Salience of Different Aspects of the Immigration Issue in Popular German Online Media over Time

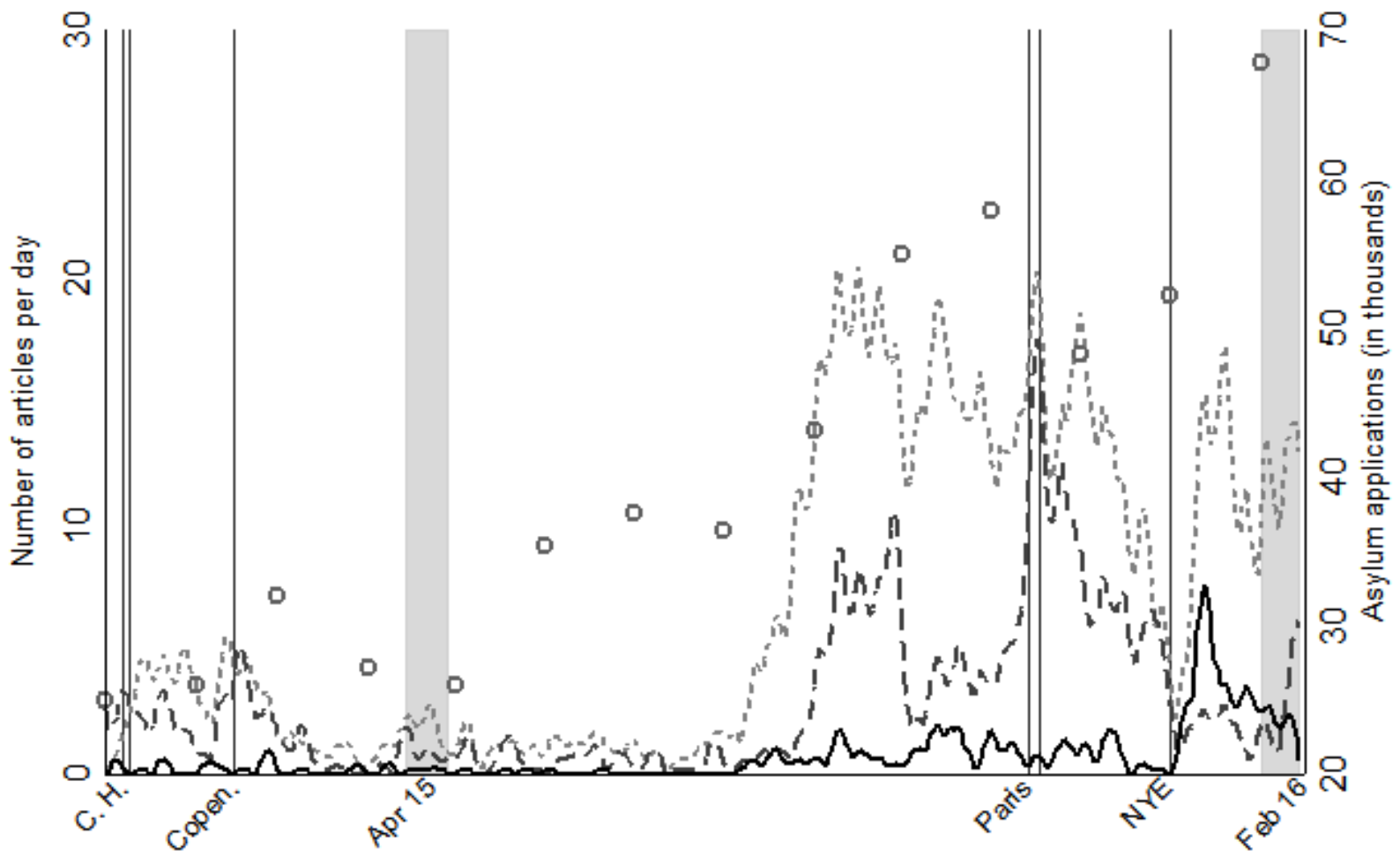

Articles referring to immigration and ...

$$
\text { -. -..--Africa / Middle East - - - -Islam — sexual violence }
$$

Note: based on the number of daily articles from Spiegel Online, Welt Online and Zeit Online (topics not mutually exclusive), source: Nexis (search string in online appendix), grey circles are monthly asylum applications (right axis), grey bars indicate survey waves.

Salient events and attacks: C. H.: Charlie Hebdo \& Jewish supermarket (Jan 15); Copen.: cultural centre and Synagogue in Copenhagen (Feb 15); Paris: Bataclan and others as well as cancellation of soccer game in Germany (Nov 15); NYE: New Year's Eve 15/16

As Figure 1 indicates, the salience of the immigration issue somewhat abated by the end of 2015. This changed abruptly in the days after NYE 2015/16 when the circumstances of the 
assaults were gradually uncovered by the media. Now the attention on immigration from Arabic or (North-)African as well as Islam strongly increased. The political right often explicitly framed refugees as being directly dangerous to the native population and harmful to Western values in the aftermath of these events (e.g., Meisner and Wischmeyer, 2016; Weiland, 2016). The assaults also boosted the opposition of the PEGIDA movement, by emphasising the danger of "Islamization." But the events were not only discussed by the far-right. For example, Germany's Federal Minister of the Interior at the time referred to the 2015/16 NYE as a "turning point" in the German refugee debate, emphasising that newcomers must respect "our" (so: German) values and culture (Spiegel Online, 2016). ${ }^{3}$ Immigrants were hence prominently discussed as emanating symbolic threats, harming what is seen as the established norms and values (see Hainmueller and Hopkins, 2014: $234 \mathrm{ff}$.$) .$

Finally, Figure 1 shows that the previously niche topic of immigration and sexual violence suddenly became important after NYE, as this was exactly what these events were about. This was also addressed by public speakers, especially from the far-right, who stressed the "sexual danger" that the inflow of male migrants from Arab and North-African countries would cause (Weiland, 2016). For example, the far-right party Pro NRW slandered refugees as "testosterone-ridden newcomers hunting down young native women" (Meisner and Wischmeyer, 2016). Hence, immigrants were not only discussed as being symbolically threating, but also as threats to the collective as well as to the individual safety (de Rooij et al., 2015), the latter especially concerning native women.

\section{Hypotheses}

Several important events took place between our two survey waves: the fatal attacks in the inner city of Paris, the cancelation of a football match in Germany due to terror threat (both in November 2015), and the assaults on NYE 2015/16 in Germany. This makes the isolation of the effect of a single event impossible with our data. However, given that all events were part of the broader discourse of the "migrant crisis," we think that the effects of 
the later events are generally not independent of the previous ones. This is because these events all happened in relatively short time and they share a common core - they were all connected to the inflow of refugees by many public speakers. Thus, we assume that the effect of an event carries over and gets, at least partly, reactivated with each new event. This means that the effect of the most recent event of our analysis may cumulatively include parts of the events before. Since our survey was carried out in Germany, where the most recent prominent event in this chronology happened (the assaults on NYE 2015/16), we hypothesize that general public acceptance of immigrants significantly decreased in the second wave of our survey because the events increased both safety and symbolic threat perceptions (de Rooij et al., 2015).

Hypothesis 1: Immigrants are less accepted after NYE, irrespective of their characteristics. (General Threat-Hypothesis)

As discussed, the NYE assaults were clearly linked to the inflow of male refugees coming from North-African and Arab - and predominantly Muslim - countries by many public speakers. This may create, or reinforce, a "racial image" (Blumer, 1958) of particular outgroups. The potential economic burdens of migration, on the other hand, were addressed to a much lesser extent after the events and we therefore expect the evaluation of economic characteristics to be unaffected by the events. Symbolic and safety threats should therefore be primarily connected to those immigrant characteristics which were associated with the perpetrators of these events by political and public speakers:

Hypothesis 2: A negative change in public acceptance of immigrants after NYE 2015/16 depends especially on three factors: their country of origin, being Muslim, and being male. (Specific Threat-Hypothesis)

Deriving a hypothesis regarding changes in the acceptance of refugees between both waves is less clear. On the one hand, many public speakers linked the events in general, and the assaults of NYE in particular, directly to the inflow of refugees, as discussed above. Moreover, evidence indicates that respondents who primarily have asylum seekers in mind 
when thinking about "immigrants" tend to be more restrictionist (Blinder, 2015). On the other hand, several studies found that people were more positive towards immigrants if the reasons of forced migration, such as repression or persecution, were made explicit or emphasized (Bansak et al., 2016; Hainmueller and Hopkins, 2015; Newman et al., 2013). With rising refugee rates, the media also increasingly focused on the war in Syria, other humanitarian crises in the refugees' countries of origin, and the dramatically large number of migrants who died trying to cross the Mediterranean Sea. Such shocking information may also increase natives' readiness to help.

Our study is the first to test whether the perceived threat caused by external events outperforms the humanitarian concerns which generally determine attitudes toward persecuted immigrants. Since both effects are plausible, we formulate two competing hypotheses:

Hypothesis 3a: Immigrants who want to enter Germany because they are fleeing from persecution are less accepted in the second than in the first wave. (Refugee Threat-Hypothesis)

Hypothesis 3b: Immigrants who want to enter Germany because they are fleeing from persecution are more accepted in the second than in the first wave. (Humanitarian Needs-Hypothesis)

Finally, as the most recent event under study was mainly about sexual assaults against women, we also test whether the event affected male and female respondents differently, hypothesizing that sexual threat perceptions are stronger for female than for male respondents (cf. Navarrete et al., 2010). Female respondents should thus be more concerned about individual safety threats compared to males.

Hypothesis 4: The negative change in the acceptance of immigrants who are male or Muslim or from Arab or North African countries is stronger for female than for male respondents. (Sexual Threat-Hypothesis)

In an innovative and unique design, we combine the analysis of external events (as in Finseraas and Listhaug, 2013; Hopkins, 2010; Legewie, 2013) with the strengths of multi- 
factorial survey experiments (as in Bansak et al., 2016; Hainmueller and Hopkins, 2015; lyengar et al., 2013) relying on intra-individual variation over time to test these hypotheses.

\section{Research Design, Data and Methods}

Our data come from a two-wave panel survey of a convenience online pool administered through the SoSci-Panel. ${ }^{4}$ Initially, 4,991 individuals were invited of which 1,352 participated in the first wave and 738 again in wave 2 . The drop-out rate hence amounts to $45.41 \%$. We tested for selection into the second wave by using a logistic regression where dropout after wave 1 was regressed on the mean rating of each respondent across all immigrant profiles in wave $1^{5}$ as well as on a large number of covariates. ${ }^{6}$ Neither a single variable nor the complete model was significant (LR-Test: Chi2 $(\mathrm{df}=12)=18.45, \mathrm{p}=0.103)$. Thus, there is no evidence indicating that unit non-response was selective.

\section{Outcome: Acceptance of Immigrants}

Respondents were asked to rate their willingness to give various fictive immigrant profiles the right to live in Germany on a 7-point Likert-scale. ${ }^{7}$ Figure 2 presents the distributions of the dependent variable separately for both waves, showing that acceptance of immigrants somewhat declined between both waves, from an average value of 5.12 in wave 1 to 4.88 in wave 2. Public opinion thus seems to have shifted during this time and we will dissect these changes in our analysis below. 
Figure 2: Distribution of dependent variable (in percent)
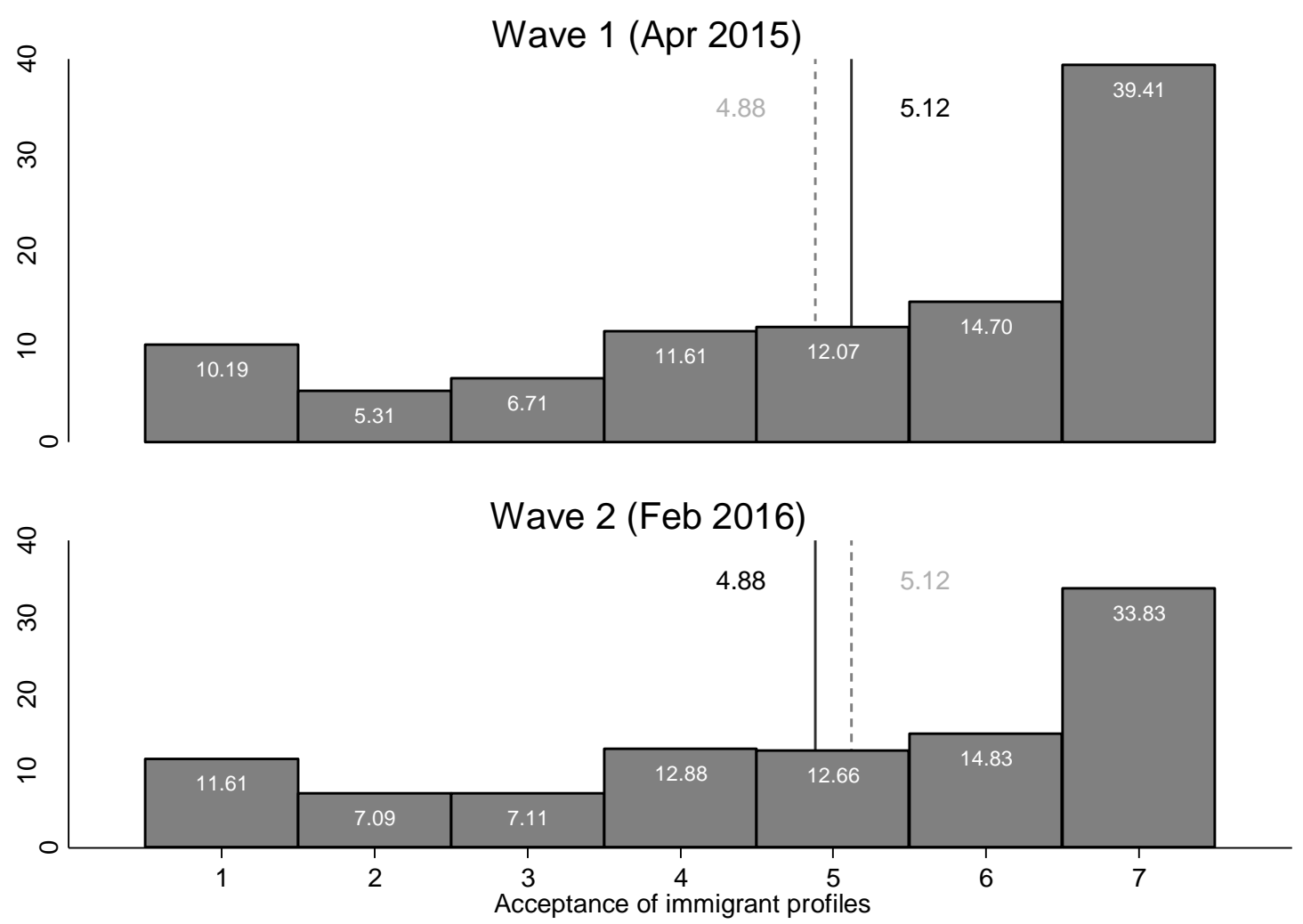

Note: vertical lines indicate mean values in the first and second wave

\section{Treatments: Immigrant Characteristics}

Each immigrant profile consists of the six attributes: gender, country of origin, reason for migrating, qualification, language skills, and religious denomination. Table 1 presents all six characteristics with their values. Qualification and language skills are, at least partly, indicators of economic characteristics, while country of origin and religious denomination indicate cultural distance. The reason for migrating was included to test whether respondents differentiated between those who came as refugees, i.e. fleeing from political persecution, and those who came for economic reasons. We included three countries of origin: Lebanon, Kenya, and France. While the latter is culturally similar to Germany, Lebanon and Kenya represent one country from the Middle East and one from Africa, two culturally more distant areas. These particular countries were chosen because they were not in the centre of public debates and therefore not confounded with specific aspects like 
war. Furthermore, they have religiously mixed populations, making the different combinations of countries and religious denominations plausible. For a detailed description of these profiles and their attributes and values also see the online appendix A as well as Czymara and Schmidt-Catran (2016).

Table 1: Immigrant profile characteristics

\begin{tabular}{ll}
\hline Attributes & Values \\
\hline Gender & (1) Female \\
(2) Male \\
Reason for immigration & (1) Prospective job in Germany \\
& (2) Better live, no prospective job \\
(3) Political persecution \\
County of origin & (1) France \\
& (2) Lebanon \\
(3) Kenya \\
Lualification & (1) Low ("low qualification”) \\
Language skills & (2) High ("university degree”) \\
Religion & (1) Bad \\
& (2) Good \\
& (1) No religion \\
& (2) Christ \\
& (3) Muslim
\end{tabular}

Respondents were asked to rate the same set of 14 profiles in each wave, with randomized order. The 14 profiles contain a specific set of all possible combinations of attribute values. We drew a sample from all possible combinations in such a way that the values of each attribute tend to occur with the same frequency (balance) and to be uncorrelated (orthogonality). ${ }^{8}$ This allows the estimation of the attributes' causal effects under the assumption that interaction effects between them are negligible (Dülmer, 2007: 386). For two reasons our set is only approximately balanced and orthogonal: firstly, because it is practically impossible to divide all values for all attributes equally in 14 profiles and, secondly, because we imposed a restriction for the highly implausible combination of immigrants originating from France and migrating because of political persecution. This is no drawback, however, since "semi-orthogonal" designs can be more efficient than perfectly orthogonal ones, e.g. in case of asymmetric numbers of values across attributes (Dülmer, 2016; Kuhfeld et al., 1994) - which is true for our set. Still, our set comes very close to the ideal of perfect balance and orthogonality. ${ }^{9}$ Table OA1 (online appendix) shows the 
correlations between the attribute values and Table A1 (appendix) their descriptive statistics.

To keep the approximate orthogonality, rating all immigrant profiles was programmed as mandatory. $5.1 \%$ of the respondents were excluded from the analysis because they dropped out during this part of the survey in the first wave (69 in total) and $2.57 \%$ in the second wave (19 in total). Thus, item non-response in the main part of our survey is negligible.

We rely only on the data of those respondents who rated all 14 immigrant profiles in both waves for our analysis. This allows the direct comparison of the effect sizes of each immigrant attribute because the same respondents rated the same outcome on the same scale for the same set of immigrant profiles in both waves. We furthermore excluded respondents which had missing values on one of the respondent-level variables controlled in the regression analysis. In total, our final sample contained 644 respondents rating 14 immigrant profiles at two time points, leaving us with a total of 18,032 profile ratings.

Treatment: Events during the "migration crisis"

Wave 1 of the survey took place in April 2015 and Wave 2 one month after NYE. To capture changes between both waves, we generated a dummy variable $t$ ( $0=$ first wave, $1=$ second wave). As we rely on intra-individual variation for the estimation, this time-effect is not correlated with unobserved heterogeneity and therefore less prone to omitted variable bias. Furthermore, since the set of immigrant profiles was identical in both waves, we can estimate how the effects of the immigrant characteristics changed after the events by accounting for an interaction between the profile characteristics and $t$.

\section{Respondents' Characteristics}

As the immigrant profile attributes are uncorrelated with respondents' characteristics by design, it is not strictly necessary to control for them to obtain unbiased effects of the immigrant profiles. Nevertheless, we included several characteristics of the respondents in 
our analysis out of general interest. These variables are: gender, employment status (fulltime, part-time, unemployed, out of labour force), education (low, medium, high), religious denomination (Christian, other, none), age, living in East-Germany, and number of migrant friends (many, some, few, none). Table A1 in the appendix provides their summary statistics.

\section{Validity and Representativeness}

Our design is (quasi-)experimental and therefore does not require a representative sample to yield valid results. However, as we are dealing with a sample from an online access pool, the issue of representativeness shall be briefly discussed to demonstrate that our results are likely to be generalizable. Table A2 in the appendix presents the distribution of the sociodemographic variables age, gender, and education in the German population and in our survey. With respect to gender, our sample seems to be perfectly representative. With respect to age we observe the expected overrepresentation of young and underrepresentation of older people but overall this effect appears not dramatic except for those being older than 74 .

We observe a strong overrepresentation of both low and high educated individuals compared to those with medium education. This is due to the fact that we oversampled low educated people to compensate their usual underrepresentation in online panels.

Based on the weighted multivariate distribution of age, gender, and education in the German Socio-Economic Panel, we constructed weights for our data set and compared the results from an unweighted and a weighted analysis. We performed a test proposed by DuMouchel and Duncan (1983), which indicates that the weighted estimates do not differ significantly from those in the unweighted models. Therefore, we present the unweighted analysis in the paper. The weighted effects are in general very similar, but with slightly different significance levels for a few variables. We report a comparison between weighted and unweighted models in Figures OA1 and OA2 (online appendix). 


\section{Statistical Model}

We estimated three-level mixed models with the ratings at level-1, nested in the survey wave, nested in respondents. This structure accounts for the statistical dependencies of the multiple ratings by each respondent (via level-3) and for the additional dependency of the respondents' ratings within one survey wave (via level-2). We treat the 7-point Likert-scale as quasi-metric and therefore estimate linear random effects models. ${ }^{10}$

\section{Results}

Table A3 (appendix) presents the results from a series of four models. Model M0 is an empty model showing that the mean rating across all profiles and time is almost exactly 5 . Since 7 is the most positive value, respondents rated immigrants rather positively on average. The model furthermore indicates that most of the variance is located at the immigrant profile level (2.18), meaning that respondents did indeed react to the varying immigrant characteristics. However, there is also a considerable amount of variance between respondents (1.52) and, more important for this study, between waves (0.61).

Model M1 adds the immigrant characteristics and the wave dummy. Because both are uncorrelated by design, the coefficient of $t$ indicates that the average acceptance of immigrants has significantly declined in the second wave $(-0.241, p<0.001)$, supporting hypothesis $\mathrm{H} 1$. This effect represents the general negative effect of the events between both waves and may thus be understood as an equivalent to the event effects of the studies discussed above. This negative effect is about as large as the discrimination against Muslims compared with non-religious immigrants. Since the effects of the immigrant characteristics in Model M1 are averaged over both waves and we are primarily interested in the changes between waves, Model M1 is not our main interest. Nevertheless, we briefly review the estimated parameters. Most interestingly, immigrants fleeing persecution are more likely to be accepted than those who come for economic reasons but have a prospective job, which is by far the strongest effect in the model, while those who come for a better living without having a job opportunity are consigned to the lowest rank. This already 
indicates a strong general willingness to help refugees in our sample. Moreover, male immigrants are more accepted than females, and all other effects are in the direction one would assume: immigrants from Kenya or Lebanon are less accepted than immigrants from France, immigrants with high qualifications and good language skills are more accepted than immigrants with low ones., and Muslim immigrants are less accepted than nonreligious or Christians (for a more detailed discussion of similar results see: Czymara and Schmidt-Catran, 2016).

Model M2 adds interaction effects between $t$ and all immigrant characteristics, plotted in Figure 3. These interactions test how the effects of immigrant profile characteristics have changed between both waves. They can thus be understood as a test for the universality of the $t$ effect estimated in M1 (mind that the main effect of $t$ in M2 is now conditional for a female, non-religious migrant from France coming for a better life with low qualification and low language skills). An LR-test comparing models M1 and M2 indicates that, overall, the effects of immigrant characteristics have indeed changed between waves $\left(\mathrm{Chi}^{2}=19.09, \mathrm{p}<0.05\right)$. However, looking at the single coefficients of the interactions in $\mathrm{M} 2$, we see that only the changes in the effects of country of origin and reason for immigration are statistically significant. 
Figure 3: Coefficients plot for main and interaction effects

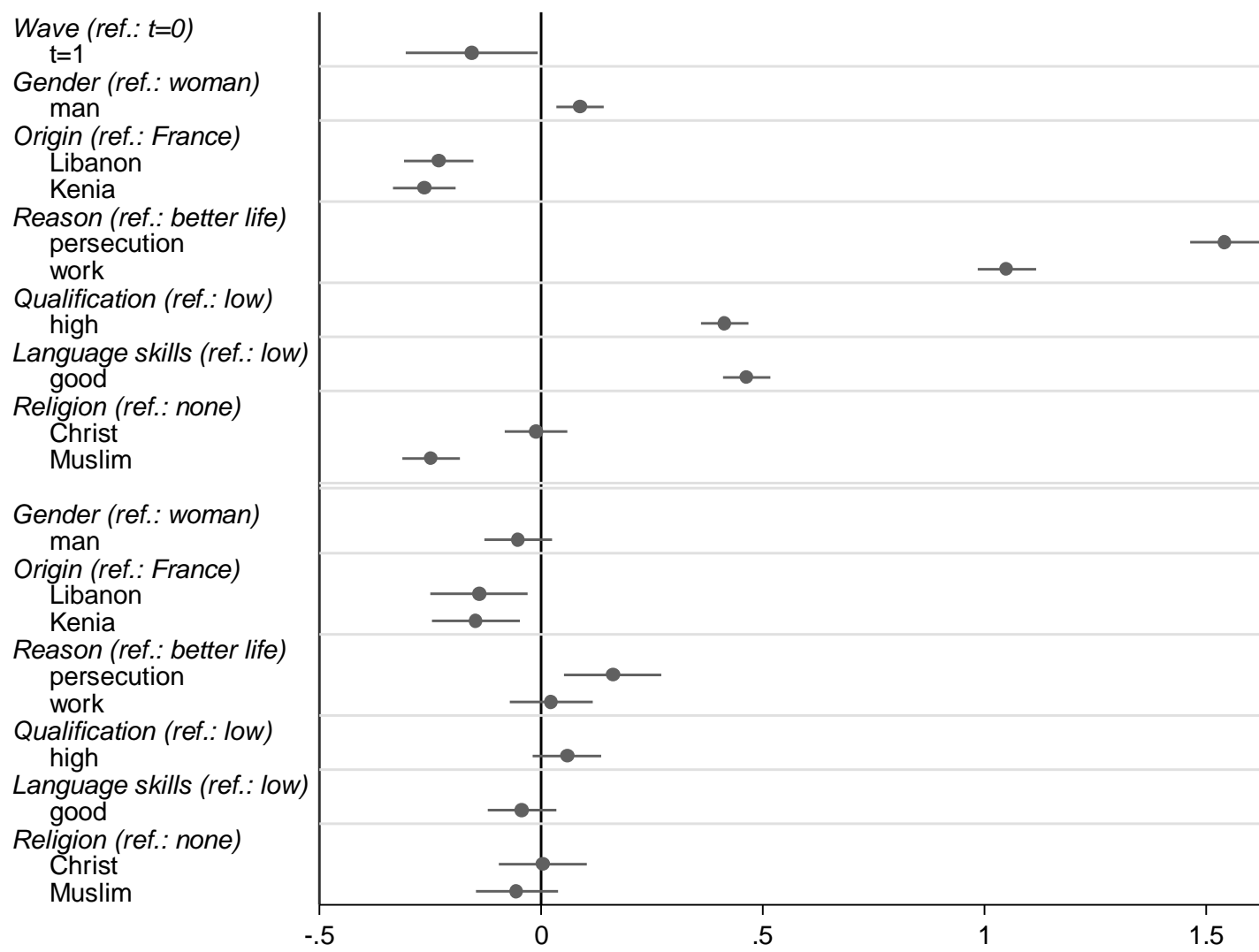

Note: point estimates and 95\% confidence interval, based on model M2 (Table A1 in the appendix)

The most outstanding effect relates to immigrants fleeing political prosecution - who were strongly favoured over those who come for a better living in wave 1 already (1.542, $p<0.001$ ). They are favoured even more in wave 2 (effect at $t=2: 1.705, p<.001$ ). This indicates that humanitarian needs can, at least in this hypothetical situation, by far outperform potential threats, clearly favouring hypothesis $\mathrm{H} 3 \mathrm{a}$ over $\mathrm{H} 3 \mathrm{~b}$.

On the other hand, our German respondents in the first wave strongly preferred immigrants from France over those from Lebanon $(-0.230, p<0.001)$ or Kenya $(-0.263$, $p<0.001$ ), two countries culturally more distant to Germany. In line with our expectations, M2 reveals that these origin-effects became even stronger in the second wave (conditional effect of Lebanon after event: $-0.369, \mathrm{p}<0.001$; Kenya: $-0.409, \mathrm{p}<.001)$. Thus, the events, especially NYE, had an additional negative effect on the acceptance of immigrants from 
Africa or the Middle East on top of the general negative effect of cultural distance, providing solid support for the cultural threat hypothesis (H2).

While not statistically significant, there are also substantive changes regarding gender: While male immigrants were preferred over females in the first wave $(0.089$, $p=0.001$ ), this is no longer the case in the second wave (conditional effect of male immigrant profile in the second wave: $0.038, p=0.167)$. The model thus lends some support to the expectation that the events, and especially NYE, affected the acceptance of male immigrants (hypothesis $\mathrm{H} 2$ ), though the change in the gender effect itself is not very strong and not statistically significant.

Changes in the effects of qualification level and language skills are rather small compared to their main effects and not statistically significant. It thus seems that, as expected, the events hardly affected economic aspects. But interestingly, the same also applies to religious denomination: While Muslims were the least accepted by a large degree in wave $1(-0.247, p<0.001)$, the additional negative effect for Muslims in wave two is much weaker than expected and also not statistically significant (effect at $t=2:-0.301, p<0.001$ ). Interestingly, neither the Islamist terror attacks nor the recent disproportionally high influx of Muslims significantly altered the public acceptance of Muslim migrants in our sample.

Finally, we added three-way interaction terms between the immigrant characteristics, $t$, and respondents' gender in Model M4 to test whether the changes of effects over time differ for female and male respondents. Because these parameters are quite complex, we do present them as marginal effects of the immigrant characteristics here, conditional on respondent's gender and $t$. Moreover, we show only those effects which changed significantly between the two waves in M2. These marginal effects are shown in Figure $4(\mathrm{a}-\mathrm{c})$, the full model can be found in the appendix (Table A1). 
Figure 4: Marginal effects of immigrants' characteristics, conditional on respondent's gender and time point

a) Marginal effects of male immigrant profiles (ref.: female)

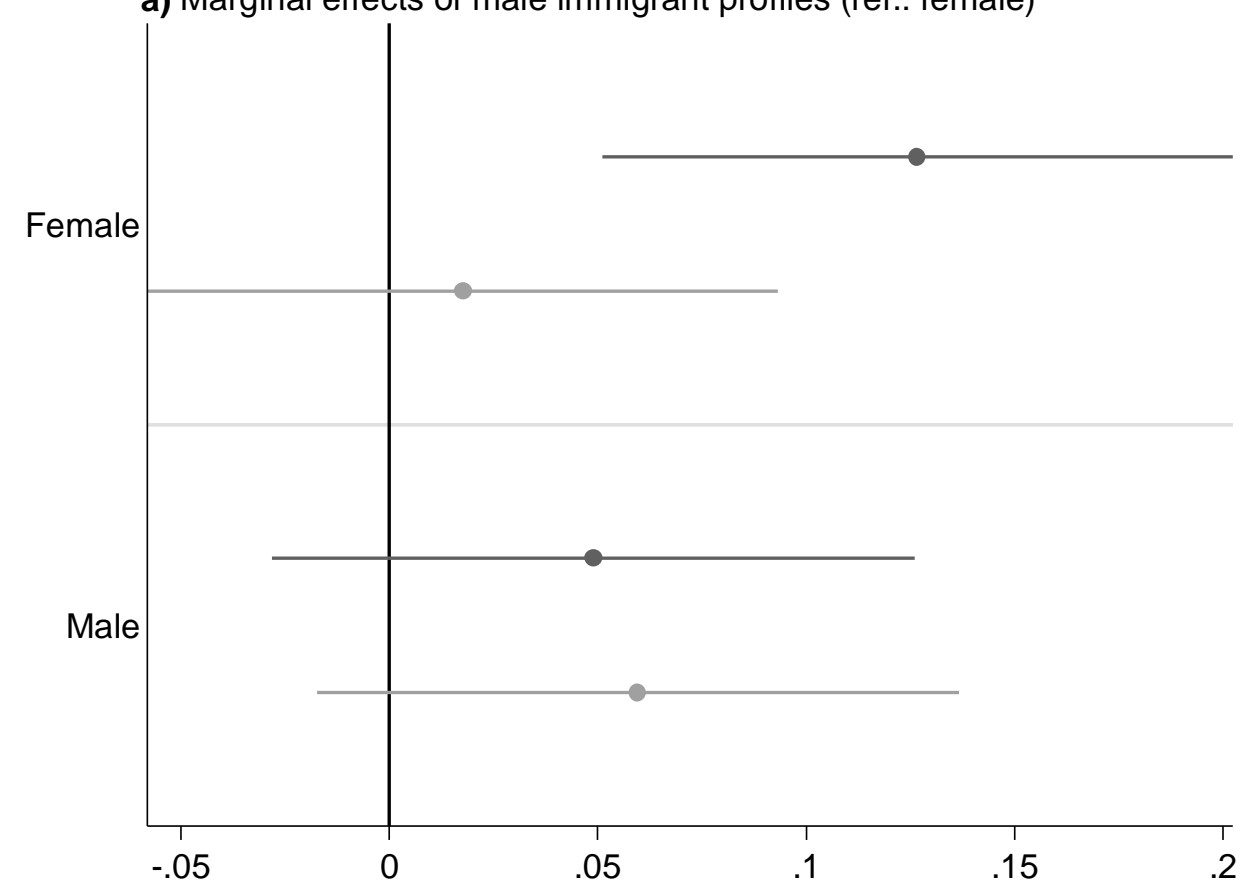

b) Marginal effects of immigrant profile's origin (ref.: France)
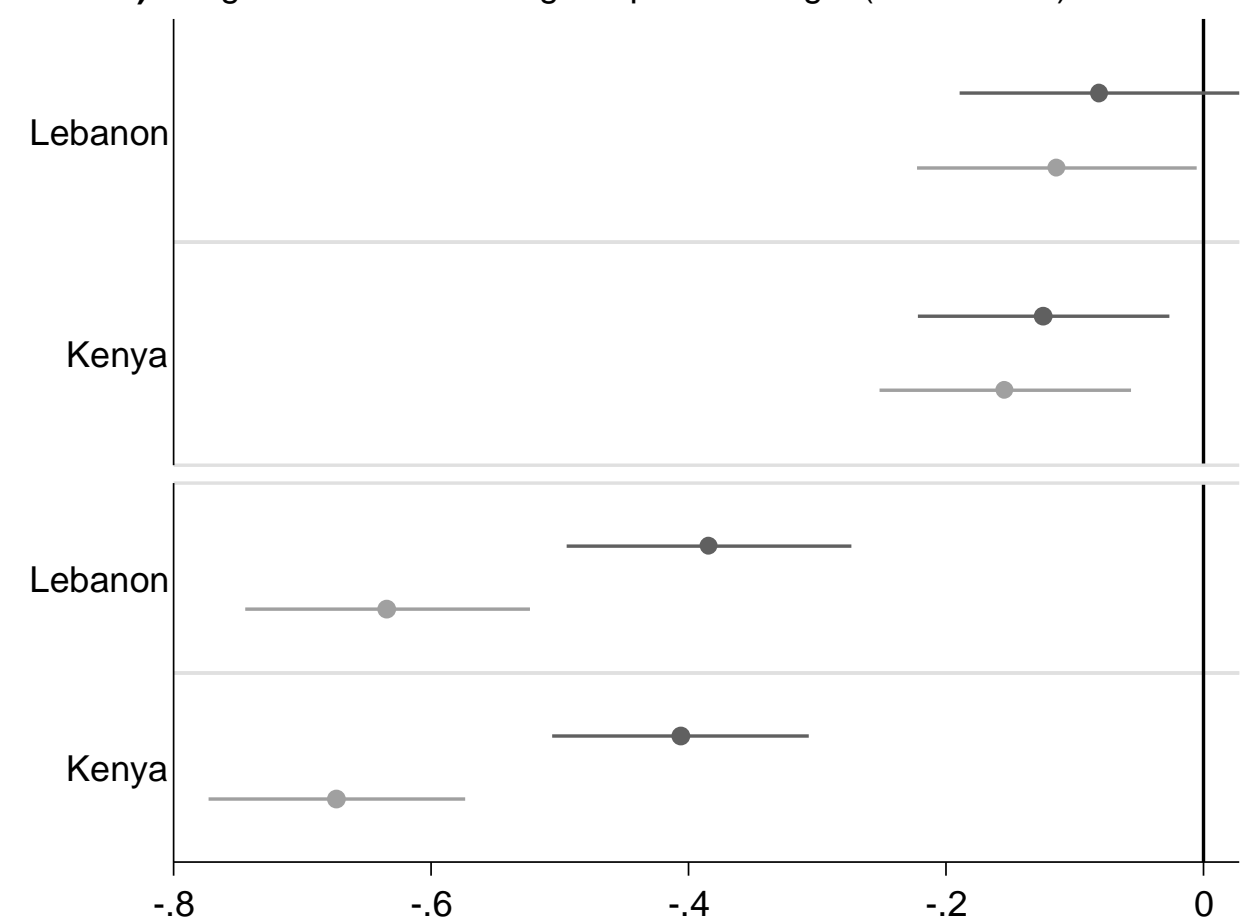
c) Marginal effects of immigrant profile's reason of migration (ref.: better life)

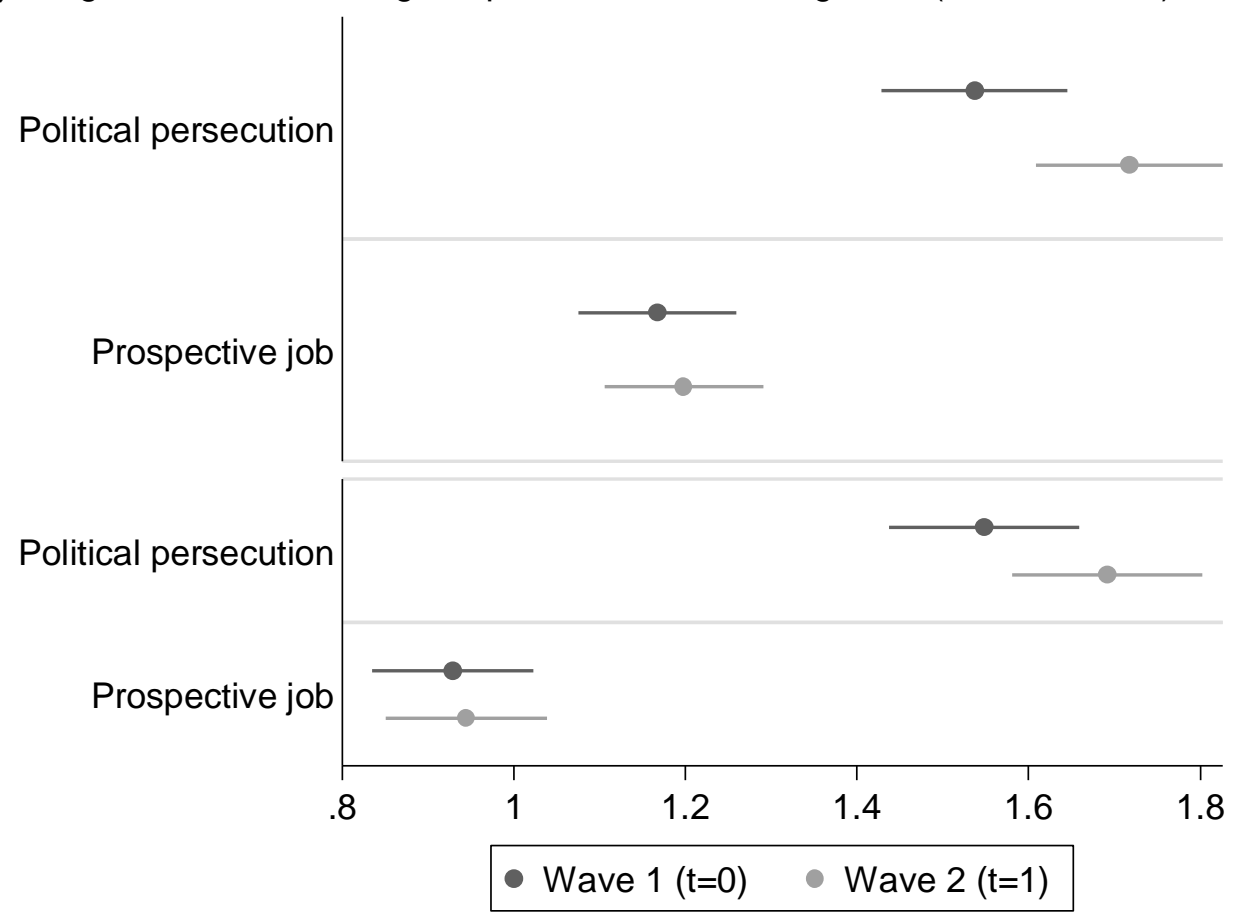

Note: point estimates and 95\% confidence intervals, based on model M4 (Table A1 in the appendix).

Interestingly, Figure 4a reveals that the initial preference for male immigrants is mainly due to female respondents $(0.127, p=0.001)$ whereas men were largely indifferent here $(0.049$, $p=0.214)$. Moreover, the diminishing of the preference for male migrants in the second wave is also largely due to the statistically significant drop of female approval of males $(-0.109$, $\mathrm{p}=0.046)$, practically resulting in female indifference about gender at $t=2(0.018, \mathrm{p}=0.648)$. This lends some support to the hypothesis that individual safety concerns play a role for women but not for men $(\mathrm{H} 4)$.

Deeper analysis also uncover that men were the main drivers behind the decrease of acceptance regarding immigrants from Lebanon or Kenya in wave 2 reported in model M2 (cf. Figure 4b). While female respondents exhibit a stable and rather modest negative preference regarding an immigrant's origin over time, men show a quite strong decline in addition to their already very negative ratings at wave 1 (Lebanon: $t=0:-0.384, p<0.001$, $t=1:-0.634, p<0.001$, change: $-0.250, p=0.002$; Kenya: $t=0:-0.406, p<0.001, t=1:-0.673$, 
$p<0.001$, change: $-0.267, p<0.001)$. This result is not in line with the expectations from hypothesis $\mathrm{H} 4$ and difficult to explain ad hoc.

The increasing support for immigrants fleeing prosecution reported before is almost irrespective of gender. However, the change for women $(0.180)$ is statistically significant at the $1 \%$ level $(p=0.006)$ while the effect's increase for men $(0.143)$ doesn't reach the $5 \%$ level of significance $(p=0.072)$. Finally, neither men nor women appear to have significantly altered their view of Muslim immigrants between both waves.

\section{Summary and Discussion}

Our results indicate that the public acceptance of immigrants in Germany decreased significantly between April 2015 and January 2016. This change can be attributed to several events: the strong increase of refugees, several fatal attacks of Islamist terrorism, and the assaults of New Year's Eve 2015/16 happening shortly before our second survey wave. This decrease, however, does not universally relate to all immigrants in the same way. It was about twice as large for immigrants from the Middle East and Africa compared with those from France. Both areas had been specifically emphasized in the German media after NYE 2015/16, although neither of the two countries we included in our experiment (Kenya and Lebanon) were particularly in the centre of the current European immigration debate. In fact, avoiding such confounding was the reason why we opted for these countries in the first place. Thus, effects may differ for immigrants from, for example, Syria or Iraq.

But the most striking finding in our eyes is that immigrants who flee from persecution were not only by far accepted the most from the beginning, but that their initial lead even further increased over time. Given the strong increase in the number of asylum applications between both waves (cf. Figure 1), this clearly refutes explanations of exclusionary attitudes by rising out-group sizes. Be aware, however, that the effect is relative to the reference group: immigrants who come for a better living but without a prospect of a job. This also allows for the interpretation that these immigrants have become less accepted relative to refugees. Moreover, external validity may be problematic in case respondents think of 
actual asylum applicants not only as those "fleeing persecution" but also as people who come "for a better life" under the legal status of asylum seekers. We did not label either of the groups explicitly as "refugees" or "asylum seekers" to avoid being too suggestive.

In contrast to our expectations, the change in the acceptance of Muslims migrants between both waves was modest and insignificant, though the baseline of the initial acceptance of Muslims was already low. The media coverage in the first days after NYE focused mainly on reports from witnesses, who mostly described the offenders as originating from Arab- or (North-)African countries. Religion was less a manifest characteristic in this context. While not overinterpreting our finding, one could derive that this reporting did not set Islam very high on the public agenda directly after NYE.

Looking at men's and women's preferences separately, we observed that women tended to evaluate immigrants more based on gender than men, while men tended to discriminate more by country of origin. An obvious explanation for the finding that women's initial preference for male immigrants mostly vanished in the second wave is that women are primarily affected by sexual assaults. They may thus see male immigrants after NYE not only as a threat to the collective, and somewhat more abstract, security but also as threatening their concrete individual safety. It is far less clear why male respondents rejected immigrants from the Middle East and Africa even more in the second wave while this pattern was far less observable for women. Since we are not able to perfectly disentangle individual and collective safety threats and symbolic threats with our design, a clearer distinction between these three sources of threat might be helpful to explain this finding in future research.

Another weakness of our design is that it does not allow the estimation of interaction effects between immigrant characteristics. In fact, we assume that such interaction effects are negligible for the estimation of their main effects. This is a drawback of our withinvariation design where all respondents rated the same set of immigrants in both waves. However, it would be interesting to investigate whether, for example, refugees were rated less positively in the second wave if they were Muslim, also because such interactions may 
partly be confounded with main effects (cf. Dülmer, 2007: 386). Keep in mind though that our main interest in this study was not in the main effects but in the changes of effects over time.

Finally, we assume that the effect of salient events gets (partly) reactivated with each new "similar" event happening soon after. It may also be possible, however, that the effects wear off with each new event, as the public "gets more used" to such tragic events.

In sum, our findings point to a paradoxical situation: On the one hand, people are clearly supportive of migrants in need. On the other hand, however, they seem to be critical toward those who actually enter their country as refugees. Tackling this paradox can be the key to securing social cohesion in Germany and Europe in general. 


\section{Endnotes}

Cf. https://de.statista.com/statistik/daten/studie/165258/umfrage/reichweite-dermeistbesuchten-nachrichtenwebsites/.

${ }^{2}$ Also mind that none of the events mentioned before took place immediately before the first wave.

${ }^{3}$ All statements translated by the authors.

${ }^{4}$ Data and do-files for replication are available in the online appendix under the following link: [fill in link].

${ }^{5}$ The mean ratings of our outcome (the right to live in Germany) in the pre-event survey was 5.12 for those who did not drop out after the first wave and 5.24 for those who did. A simple mean comparison already indicates that the difference between both groups is not significantly different from zero at the $5 \%$ level.

6 The other covariates include gender, education, employment status, religious denomination, having migrant friends, and coming from East Germany.

${ }^{7}$ Respondents were also asked to rate the immigrant profiles with respect to the right to work and the right to receive social benefits in Germany. In this paper, we analyze only respondents' ratings of the right to live in Germany because firstly, results are generally quite similar for each of the three ratings with respect to our event treatment and, secondly, given the interest in the effect of the assaults, we theoretically expect this to affect primarily the general right to enter the country and not particularly the rights to work or receive benefits in Germany.

${ }^{8}$ We drew this sample with the \%Mktex macro for SAS from Kuhfeld (2010) using the Modified Federov algorithm; seed number: 819179.

${ }^{9}$ The goodness of such a design can be quantified by its D-efficiency, where a value of 100 indicates a perfectly balanced and orthogonal design (Kuhfeld et al., 1994). We were able to obtain a D-efficiency of 96.94 .

${ }^{10}$ We used the mixed command in Stata 14.2 to estimate the models. 


\section{References}

Bansak, K., Hainmueller, J. and Hangartner, D. (2016). How economic, humanitarian, and religious concerns shape European attitudes toward asylum seekers, Science, 354, 217222.

Blinder, S. (2015). Imagined Immigration: The Impact of Different Meanings of "Immigrants" in Public Opinion and Policy Debates in Britain, Political Studies, 63, 80-100.

Blumer, H. (1958). Race Prejudice as a Sense of Group Position, The Pacific Sociological Review, 1, 3-7.

Ceobanu, A. M. and Escandell, X. (2010). Comparative Analyses of Public Attitudes Toward Immigrants and Immigration Using Multinational Survey Data: A Review of Theories and Research, Annual Review of Sociology, 36, 309-328.

Connor, P. (2016). Number of Refugees to Europe Surges to Record 1.3 Million in 2015. Retrieved April 26, 2017, from http://www.pewglobal.org/2016/08/02/number-of-refugeesto-europe-surges-to-record-1-3-million-in-2015/.

Czymara, C. S. and Schmidt-Catran, A. W. (2016). Wer Ist in Deutschland Willkommen? Eine Vignettenanalyse Zur Akzeptanz von Einwanderern, Kölner Zeitschrift für Soziologie und Sozialpsychologie, 68, 193-227.

de Rooij, E. A., Goodwin, M. J. and Pickup, M. (2015). Threat, prejudice and the impact of the riots in England, Social Science Research, 51, 369-383.

Dülmer, H. (2007). Experimental Plans in Factorial Surveys. Random or Quota Design? Sociological Methods and Research, 35, 382-409.

Dülmer, H. (2016). The Factorial Survey: Design Selection and its Impact on Reliability and Internal Validity, Sociological Methods and Research, 45, 304-347. 
DuMouchel, W. H. and Duncan, G. J. (1983). Using sample survey weights in multiple regression analyses of stratified samples, Journal of the American Statistical Association, 78, 535-543.

DW. (2016). String of New Year's Eve sexual assaults outrages Cologne. Retrieved February 2, 2016, from http://www.dw.com/en/string-of-new-years-eve-sexual-assaults-outragescologne/a-18958334.

Finseraas, H., Jakobsson, N. and Kotsadam, A. (2011). Did the Murder of Theo van Gogh Change Europeans' Immigration Policy Preferences? Kyklos, 64, 396-409.

Finseraas, H., and Listhaug, O. (2013). It can happen here: The impact of the Mumbai terror attacks on public opinion in Western Europe, Public Choice, 156, 213-228.

Hainmueller, J. and Hopkins, D. J. (2014). Public Attitudes Toward Immigration, Annual Review of Political Science, 17, 225-249.

Hainmueller, J. and Hopkins, D. J. (2015). The Hidden American Immigration Consensus: A Conjoint Analysis of Attitudes toward Immigrants, American Journal of Political Science, 59, $529-548$.

Hopkins, D. J. (2010). Politicized Places: Explaining Where and When Immigrants Provoke Local Opposition, American Political Science Review, 104, 40-60.

lyengar, S. et al., (2013). Do attitudes about immigration predict willingness to admit individual immigrants? Public Opinion Quarterly, 77, 641-665.

lyengar, S. and Kinder, D.R. (2010). News That Matters: Television and American Opinion. 2. Chicago: University of Chicago Press.

Knobbe, M. et al. (2015). Locals Step In to Help Refugees in Need. Retrieved October 21, 2016, from http://www.spiegel.de/international/germany/refugees-encounter-willing-helpers-ingermany-a-1048536.html. 
Kuhfeld, W. F. (2010). Marketing research methods in SAS. Experimental design, choice, conjoint and graphical techniques. Cary.

Kuhfeld, W. F., Tobias, R. D. and Garratt, M. (1994). Efficient Experimental Design with Marketing Research Applications, Journal of Marketing Research, 31, 545-557.

Legewie, J. (2013). Terrorist Events and Attitudes toward Immigrants: A Natural Experiment, American Journal of Sociology, 118, 1199-1245.

Lutz, M. (2016). Das Phänomen „taharrush gamea“ ist in Deutschland angekommen. Retrieved November 8, 2016, from https://www.welt.de/politik/deutschland/article150813517/DasPhaenomen-taharrush-gamea-ist-in-Deutschland-angekommen.html\#.

Meisner, M. and Wischmeyer, N. (2016). Rechtsextreme nutzen Köln für rassistische Hetze. Retrieved November 2, 2016, from http://www.tagesspiegel.de/politik/nach-dersilvesternacht-rechtsextreme-nutzen-koeln-fuer-rassistische-hetze/12790838.html.

Navarrete, C. D. et al. (2010). Prejudice at the nexus of race and gender: An outgroup male target hypothesis, Journal of Personality and Social Psychology, 98, 933-945.

Newman, B. J. et al. (2013). Easing the Heavy Hand: Humanitarian Concern, Empathy, and Opinion on Immigration, British Journal of Political Science, 45, 583-607.

Smiley, K. T., Emerson, M. O. and Markussen, J. W. (2017). Immigration Attitudes Before and After Tragedy in Copenhagen: The Importance of Political Affiliation and Safety Concerns, Sociological Forum, 32, 321-38.

Spiegel Online. (2016). De Maizière nennt Kölner Silvesternacht “Wendepunkt.” Retrieved November 2, 2016, from http://www.spiegel.de/panorama/gesellschaft/thomas-de-maizierenennt-koelner-silvesternacht-wendepunkt-a-1118162.html.

Weiland, S. (2016). Wie die AfD die Übergriffe von Köln instrumentalisiert. Retrieved November 2, 2016, from http://www.spiegel.de/politik/deutschland/koeln-afd-instrumentalisiert- 
uebergriffe-politisch-a-1070895.html. 


\section{Appendix}

\section{Table A1: Descriptive statistics of all variables}

\begin{tabular}{|c|c|c|c|c|c|}
\hline & $\mathrm{N}$ & Mean & Std.Dev. & Min & $\operatorname{Max}$ \\
\hline \multicolumn{6}{|l|}{ Immigrant profile characteristics } \\
\hline Gender $($ male $=1$, female $=0)$ & 18,032 & 0.50 & 0.50 & 0 & 1 \\
\hline \multicolumn{6}{|l|}{ Country of origin (ref. = France) } \\
\hline Lebanon & 18,032 & 0.29 & 0.45 & 0 & 1 \\
\hline Kenya & 18,032 & 0.43 & 0.49 & 0 & 1 \\
\hline \multicolumn{6}{|c|}{ Reason for immigration (ref. = better life) } \\
\hline Political persecution & 18,032 & 0.29 & 0.45 & 0 & 1 \\
\hline Prospective job & 18,032 & 0.43 & 0.49 & 0 & 1 \\
\hline Qualification (high $=1$, low $=0$ ) & 18,032 & 0.50 & 0.50 & 0 & 1 \\
\hline Language skills (high $=1$, low $=0$ ) & 18,032 & 0.50 & 0.50 & 0 & 1 \\
\hline \multicolumn{6}{|l|}{ Religion (ref. $=$ none) } \\
\hline Christ & 18,032 & 0.29 & 0.45 & 0 & 1 \\
\hline Muslim & 18,032 & 0.43 & 0.49 & 0 & 1 \\
\hline \multicolumn{6}{|l|}{ Respondent characteristics at $t=0$} \\
\hline Gender $($ male $=1$, female $=0)$ & 644 & 0.49 & 0.50 & 0 & 1 \\
\hline \multicolumn{6}{|l|}{ Empl. status (ref. = not in labour force) } \\
\hline Full-time employed & 644 & 0.43 & 0.50 & 0 & 1 \\
\hline Part-time employed & 644 & 0.23 & 0.42 & 0 & 1 \\
\hline Unemployed & 644 & 0.11 & 0.32 & 0 & 1 \\
\hline \multicolumn{6}{|l|}{ Education (ref. = low) } \\
\hline Medium & 644 & 0.51 & 0.50 & 0 & 1 \\
\hline High & 644 & 0.43 & 0.50 & 0 & 1 \\
\hline \multicolumn{6}{|l|}{ Religion (ref. = none) } \\
\hline Christ & 644 & 0.51 & 0.50 & 0 & 1 \\
\hline Other & 644 & 0.05 & 0.21 & 0 & 1 \\
\hline Age & 644 & 45.95 & 15.22 & 17 & 80 \\
\hline Region $($ East $=1$, West $=0$ ) & 644 & 0.25 & 0.43 & 0 & 1 \\
\hline \multicolumn{6}{|l|}{ Migrant friends (ref. $=$ none) } \\
\hline Many & 644 & 0.08 & 0.28 & 0 & 1 \\
\hline Some & 644 & 0.31 & 0.46 & 0 & 1 \\
\hline Few & 644 & 0.32 & 0.47 & 0 & 1 \\
\hline
\end{tabular}

Notes: Immigrant profile-level statistics are based on 28 observations per respondent (2 waves $\times 14$ immigrant profiles), while respondent-level statistics are based on the 644 single respondents. 
Table A2: Comparison of our sample's socio-demographic composition with population

\begin{tabular}{|c|c|c|}
\hline & $\begin{array}{l}\text { SOEP } 2015 \\
\text { (weighted) }\end{array}$ & Our data \\
\hline \multicolumn{3}{|l|}{ Gender } \\
\hline Men & $48.89 \%$ & $49.07 \%$ \\
\hline Women & $51.11 \%$ & $50.93 \%$ \\
\hline \multicolumn{3}{|l|}{ Age } \\
\hline 16-29 years & $17.83 \%$ & $19.88 \%$ \\
\hline $30-44$ years & $21.67 \%$ & $23.60 \%$ \\
\hline $45-59$ years & $27.32 \%$ & $35.71 \%$ \\
\hline $60-74$ years & $20.28 \%$ & $18.94 \%$ \\
\hline 75 and older & $12.89 \%$ & $1.86 \%$ \\
\hline Mean (Std. Dev.) & $50.21(19.09)$ & 45.95 (15.22) \\
\hline \multicolumn{3}{|l|}{ Education } \\
\hline Low & $16.03 \%$ & $30.75 \%$ \\
\hline Medium & $61.38 \%$ & $41.46 \%$ \\
\hline High & $22.59 \%$ & $27.80 \%$ \\
\hline \multicolumn{3}{|c|}{$\begin{array}{l}\text { Notes: Population is defined as persons of } 16 \text { years of age and older who are living in Germany. SOEP data } \\
\text { is from the } 2015 \text { cross-national equivalence file and has been weighted with the cross-sectional weights for } \\
2015 \text {. Low education = low or intermediate secondary school; medium education = upper secondary school } \\
\text { degree and/or apprenticeship and/or vocational school; high education = tertiary education. Note that the } \\
\text { categorization of educational degrees in the SOEP differs from the categorization we use for our analysis. } \\
\text { For this comparison with the SOEP we adjusted our categorization to match the one of the SOEP. This } \\
\text { explains why the percentages of the categories low, medium, and high in Table A1 are different from the } \\
\text { percentages found in Table A2, which presents the variable education as it is used in our analysis. }\end{array}$} \\
\hline
\end{tabular}


Table A3: Full regression models

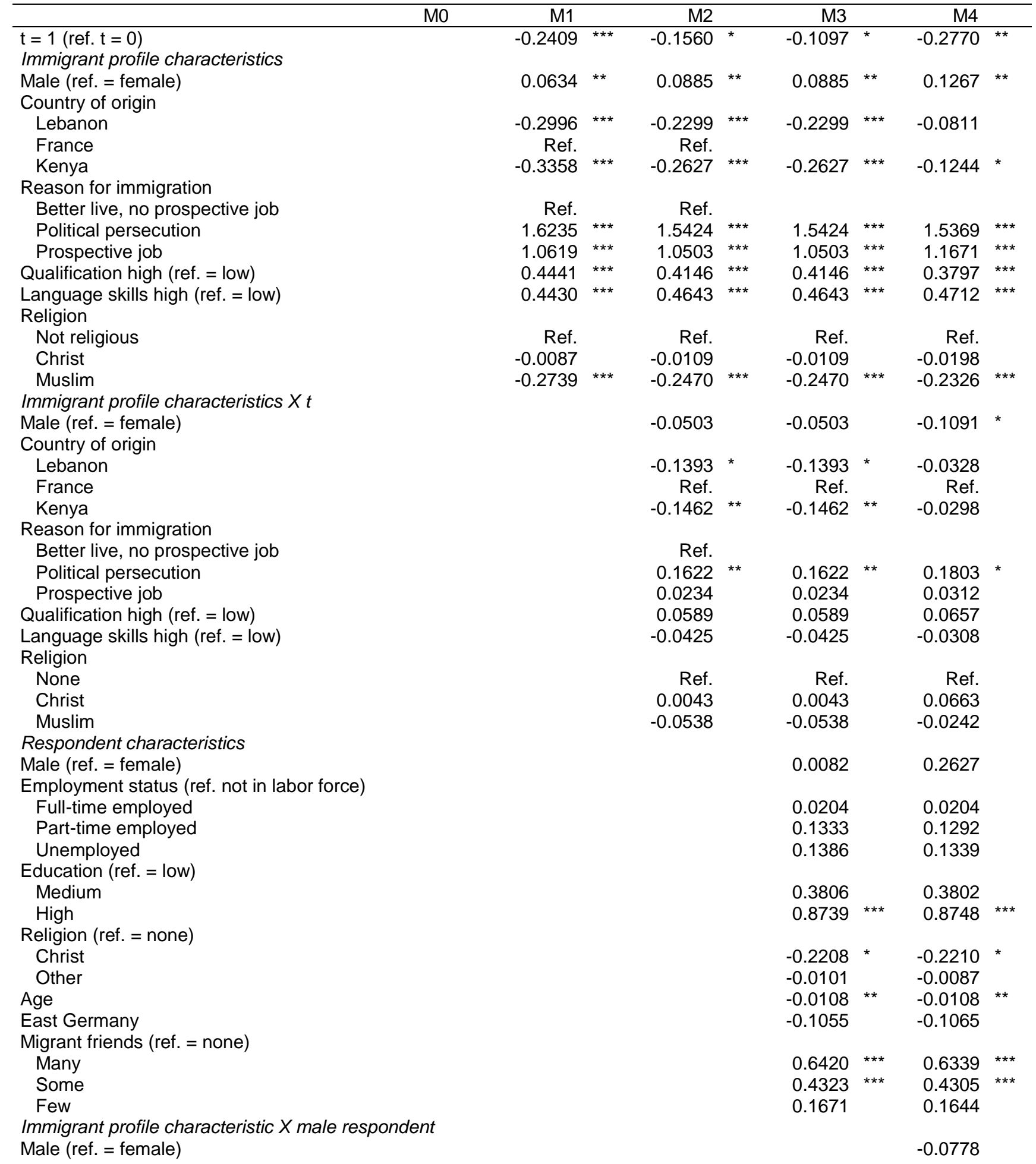

continued on next page 
continuation Table A3

Country of origin

Lebanon

$-0.3033^{* *}$

France

Ref.

Kenya

-0.2820 **

Reason for Immigration

Better live, no prospective job

Ref.

Political persecution

Prospective job

Qualification high (ref. = low)

Language skills high (ref. = low)

0.0113

$-0.2381 * * *$

0.0710

Religion

Not religious

$-0.0141$

Christ

Ref.

Muslim

0.0182

$-0.0294$

Respondent's gender Xt

Male (ref. = female)

0.3403 *

Immigrant profile characteristics $X t X$ male respondent

0.1199

Country of origin

Lebanon

$-0.2171$

France

Kenya

Reason for Immigration

Better live, no prospective job

Ref.

$-0.2373$

Political persecution

Ref.

Prospective job

Qualification high (ref. = low)

$-0.0368$

$-0.0160$

$-0.0138$

Language skills high (ref. = low)

$-0.0238$

Religion

Not religious

Ref.

Christ

Muslim

Constant

4.997

$4.073^{* \star}$

$4.030^{* *}$

$-0.1264$

Variance components

Respondent

$\mathrm{T}$

Immigrant profile

Statistics

$\mathrm{N}$ (respondents)

$\mathrm{T}(\mathrm{T} \times \mathrm{N})$

n (immigrant profiles)

Log-Likelihood

LR-Tests

LR Chi2 (df)

$1.524^{* \star *} \quad 1.539^{* \star *}$

$0.610^{* * *} \quad 0.618$ *

2.180

$1.664^{* *}$

1.539 **

1.539
0.618

1.662

644

1,288

18,032

$-34,153.82$

644

644
, 288

18,032

Prob > Chi2

$-31,882.27$

M1 vs M0

4,543.1 $<.0001$

644
1,288
18,032
$-31,872.73$
M2 vs M1
$19.09 \quad(9)$
0.0245

644
1,288
18,032
-31829.14
M3 vs M2
$87.18 \quad(13)$
$<.0001$

1,288

1,288

18,032

$-31761.38$

Notes: ${ }^{*} p<.05,{ }^{* *} p<.01,{ }^{* * *} p<.001$ (two-sided tests). 


\section{Online Appendix}

\section{A: Construction of immigrant profiles}

The immigrant profiles used in this study are standardized descriptions of immigrants which all consist of the same six attributes: gender, country of origin, reason for migration, qualification, language skills, and religious denomination. The values of each attribute where chosen in a way that minimizes implausible combinations and confounding stereotypes of, e. g. certain countries of origin. Each immigrant profile is a unique combination of the values of these different attributes (compare Table 1 for an overview of all values). Additionally, each immigrant profile was characterized by a random letter that indicated the abbreviation of a surname. An example of an immigrant profile thus reads: "Mr G. wants to migrate from Kenya to Germany because he has a prospective job. He has higher education, good skills in the German language and is Muslim." and respondents should, among other things, rate whether " $M r G$. should be allowed to live in Germany" on a 7-point scale (for the original German phrases and a more detailed discussion of the single attributes and values see Czymara and Schmidt-Catran, 2016). Because our design measures the impact of all attributes simultaneously and on the same outcome and all respondents rated the same set of immigrant profiles in both waves, it is possible to directly compare the effect sizes of the attributes with each other, under the assumption that interaction effects between the attributes are negligible. This assumption is necessary because the main effects and certain higher-order interactions of the attributes are partly confounded. Since the design is based on this assumption, it does not allow the post hoc estimation of interaction effects (cf. Dülmer, 2007: 386).

Table OA1 presents the correlations between each of the immigrant attributes. Almost all correlations between the different dimensions are weak or zero. Note that the values within each

attribute (e. g., France and Kenya) are correlated by design. Out of all other associations, only five are higher than 0.2. These correlations are all between values of the dimension Country of origin and the dimension Reason for migration - the highest correlation (0.4) is between France and Political persecution, which is the restriction we built into the design for plausibility reasons. Keep in mind, however, that we simultaneously include all attributes in our models for the analysis. In this way, even the small to moderate correlations between some attributes are controlled for and are unbiased under the assumption of negligible interaction effects between the profile characteristics. 
Table OA1: Correlations between immigrant profile characteristics

\begin{tabular}{|c|c|c|c|c|c|c|c|c|c|c|c|c|c|}
\hline & & 1 & 2 & 3 & 4 & 5 & 6 & 7 & 8 & 9 & 10 & 11 & 12 \\
\hline 1 & Gender $=$ male & 1.000 & & & & & & & & & & & \\
\hline 2 & Reason = better life & 0.000 & 1.000 & & & & & & & & & & \\
\hline 3 & Reason = political persecution & 0.000 & -0.400 & 1.000 & & & & & & & & & \\
\hline 4 & Reason = prospective job & 0.000 & -0.548 & -0.548 & 1.000 & & & & & & & & \\
\hline 5 & Religion = none & 0.000 & -0.050 & -0.050 & 0.091 & 1.000 & & & & & & & \\
\hline 6 & Religion = Christ & 0.000 & -0.050 & -0.050 & 0.091 & -0.400 & 1.000 & & & & & & \\
\hline 7 & Religion = Muslim & 0.000 & 0.091 & 0.091 & -0.167 & -0.548 & -0.548 & 1.000 & & & & & \\
\hline 8 & Origin = Lebanon & 0.000 & -0.050 & 0.300 & -0.228 & -0.050 & -0.050 & 0.091 & 1.000 & & & & \\
\hline 9 & Origin = France & 0.000 & 0.300 & -0.400 & 0.091 & -0.050 & -0.050 & 0.091 & -0.400 & 1.000 & & & \\
\hline 10 & Origin = Kenya & 0.000 & -0.228 & 0.091 & 0.125 & 0.091 & 0.091 & -0.167 & -0.548 & -0.548 & 1.000 & & \\
\hline & Qualification = high & 0.143 & 0.000 & 0.000 & 0.000 & 0.000 & 0.000 & 0.000 & 0.000 & 0.000 & 0.000 & 1.000 & \\
\hline 12 & Language skills = high & 0.143 & 0.000 & 0.000 & 0.000 & 0.000 & 0.000 & 0.000 & 0.000 & 0.000 & 0.000 & 0.143 & 1.000 \\
\hline
\end{tabular}

Notes: Pearson correlations, all variables are 0/1-coded. Correlations between variables from the same dimension are italic, other correlations larger than 0.2 are bold. 


\section{B: Comparison of weighted and unweighted analysis}

Figure OA1: Weighted and unweighted coefficient estimates from Model M2 compared
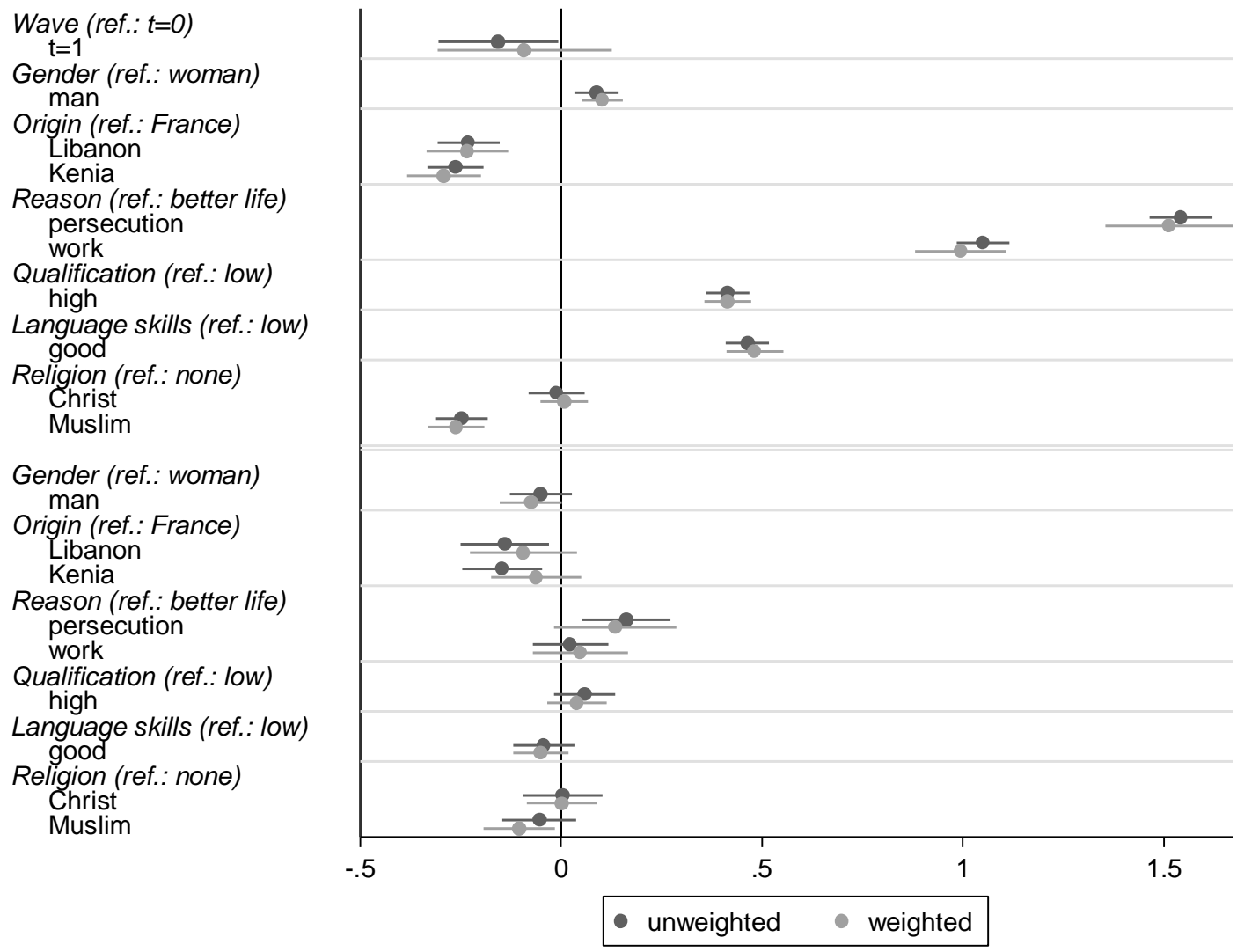

Notes: Weights have been constructed based on (weighted) SOEP data from the 2015 cross-national equivalence file. Weights are based on the multivariate distribution in a three-dimensional table of gender, age and education (compare Table A1 for more details on how age and education has been categorized). Note that the weighted and unweighted models are not significantly different from each other. 
Figure OA2: Weighted and unweighted marginal effects from Model M4 compared

a) Marginal effects of male immigrant profiles (ref.: female)

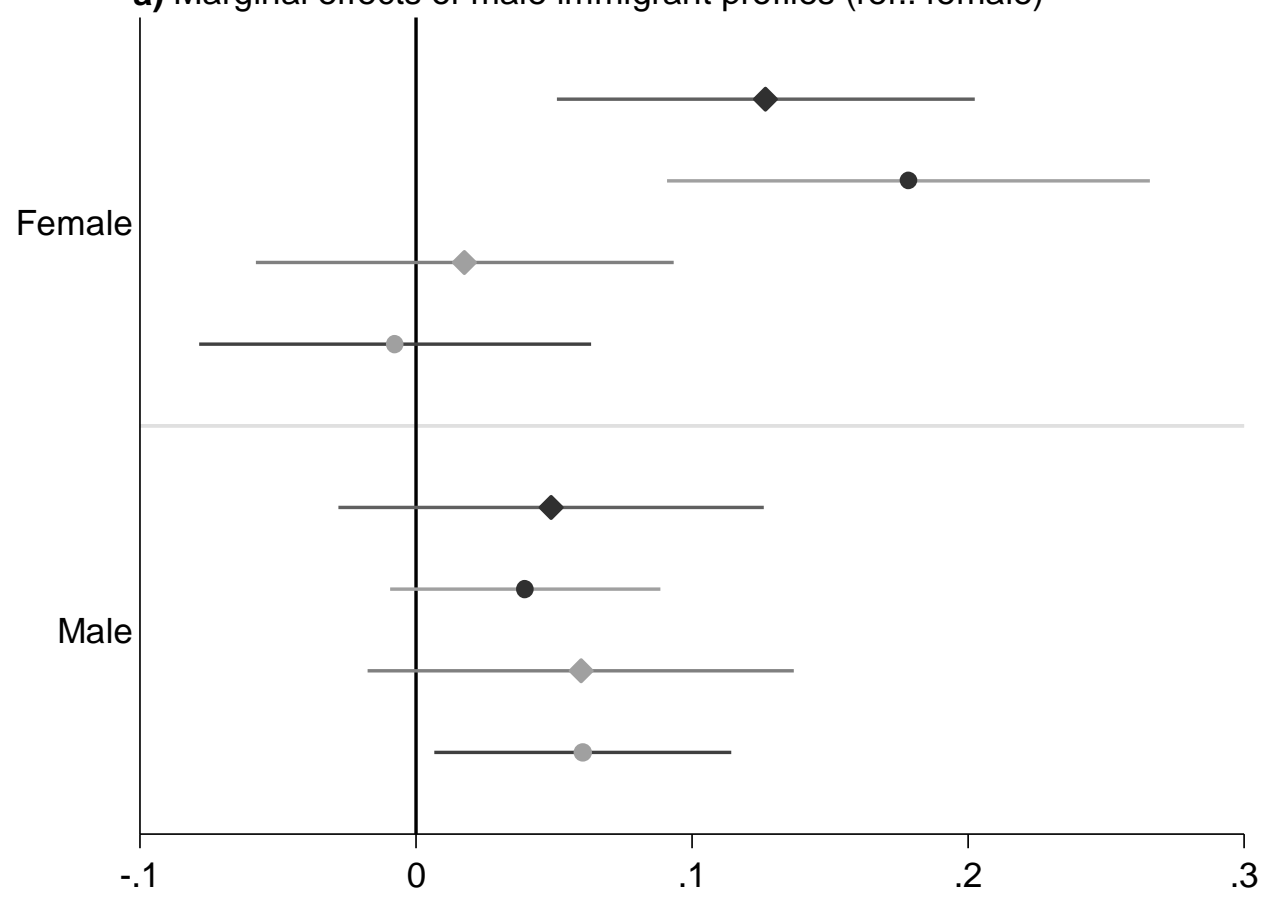

b) Marginal Effecte of Immigrant Profile's Origin (Ref.: France)

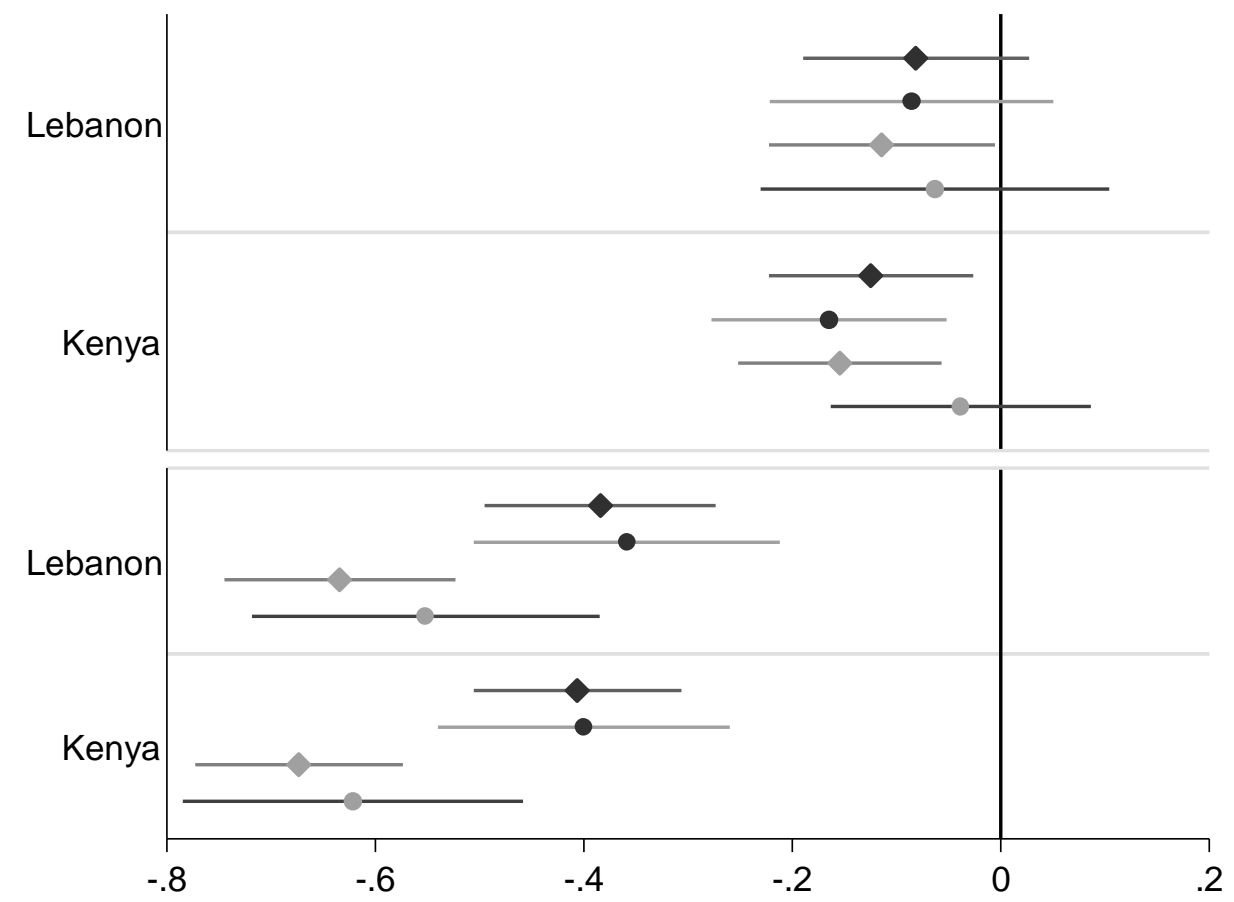


c) Marginal effects of immigrant profile's reason of migration (ref.: better life)

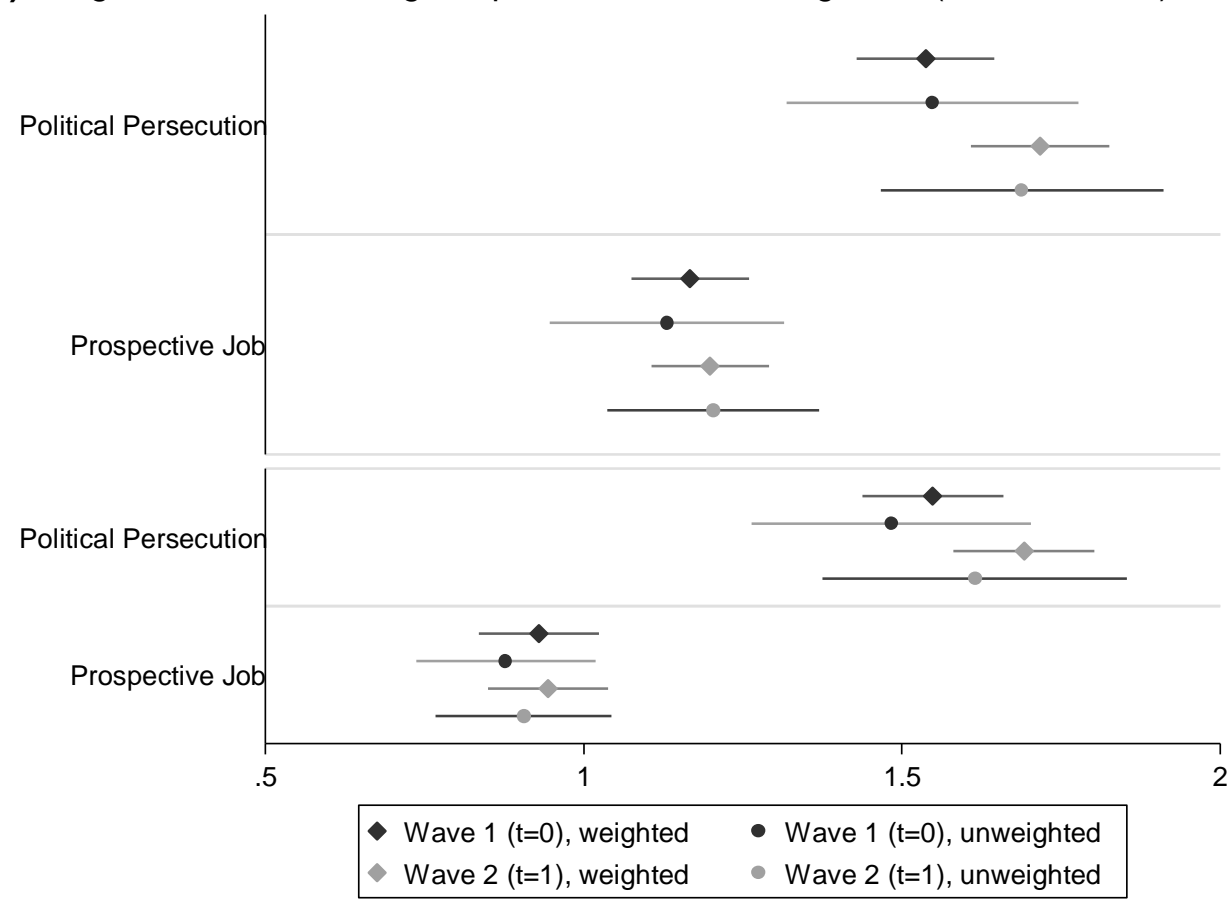

Note: point estimates and $95 \%$ confidence intervals, based on weighted and unweighted versions of model M4. Also see notes of Figure OA1. Note that weighted and unweighted models do not significantly differ from each other. 


\section{C: Search strings for Figure 1}

For articles referring to Immigration and Africa or the Middle East:

(zuwander! OR einwander! OR !migration! OR !migrant! OR !flücht! OR !flucht! OR !asy!!) AND (arab! OR !afrika! OR orient OR orientalisch OR syri! OR ((nah! OR mitt!) w/2 ost!)) AND (deutschland OR bundesrepublik OR brd)

For articles referring to Immigration and Islam:

(zuwander! OR einwander! OR !migration! OR !migrant! OR !flücht! OR !flucht! OR !asy!!) AND (islam! OR muslim! OR moslem! OR !kopftuch! OR moschee OR burka!) AND (deutschland OR bundesrepublik OR brd)

For articles referring to Immigration and sexual violence:

(zuwander! OR einwander! OR !migration! OR !migrant! OR !flücht! OR !flucht! OR !asyl!) AND (vergewaltig! OR ((gewalt OR missbrauch! OR !nötig! OR belästig!) w/2 sex!)) AND (deutschland OR bundesrepublik OR brd)

Source: Spiegel Online, Welt Online and Zeit Online provided by nexis.com (retrieved Dec 2016, updated May 2017) 